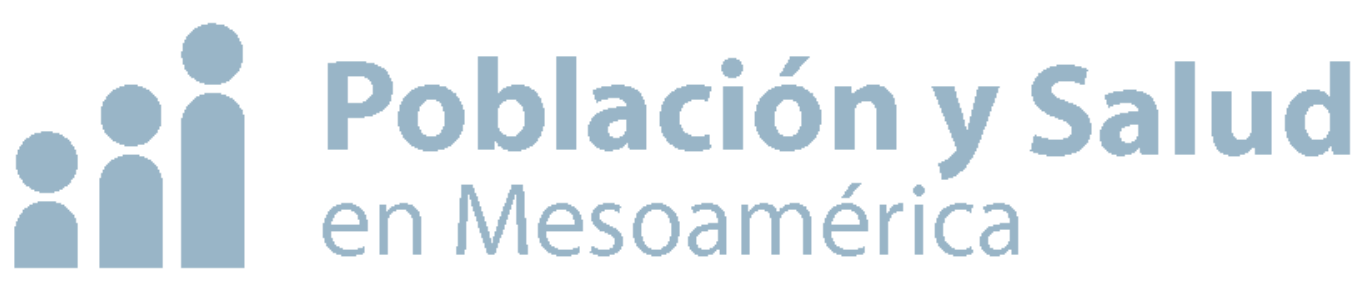

\title{
Vigilancia seroepidemiológica de la circulación del SARS-CoV-2 en 41 municipios de Honduras sin reporte de casos activos, COVID-19, del 16- 23 junio 2020.
}

Mario Rene Mejía Núñez, José Ángel Lara, Sandra Araujo Pleitez y Gilberto Ariel Ramírez

\section{Como citar este artículo:}

Mejía, M., Lara, J. Araujo, S. y Ramírez, G. (2021). Vigilancia seroepidemiológica de la circulación del SARS-CoV-2 en 41 municipios de Honduras sin reporte de casos activos, COVID-19, del 1623 junio 2020. Población y Salud en Mesoamérica, 18(2).

Doi: https://doi.org/10.15517/psm.v18i2.43261

\section{우우 (2)}

ISSN-1659-0201 http://ccp.ucr.ac.cr/revista/

Revista electrónica semestral

Centro Centroamericano de Población

Universidad de Costa Rica 


\title{
Vigilancia seroepidemiológica de la circulación del SARS-CoV-2 en 41 municipios de Honduras sin reporte de casos activos, COVID-19, del 16- 23 junio 2020.
}

\author{
Seroepidemiological surveillance of SARS-CoV-2 circulation in 41 municipalities in Honduras with \\ no report of active cases, COVID-19, June 16-23, 2020
}

Mario Rene Mejía Núñez ${ }^{1}$ José Ángel Lara² Sandra Araujo Pleitez ${ }^{3}$ Gilberto Ariel Ramírez ${ }^{4}$

\section{Resumen}

Introducción: el 12 de marzo del 2020 Honduras reporto el primer caso de COVID-19 producida por el SARS-CoV-2. A partir de ese momento, se adoptan medidas para ralentizar el contagio. Para junio 2020, se reportan casos en la mayoría de los municipios. Con el objetivo de identificar la presencia y circulación del SARS-CoV-2 y caracterizar e identificar sintomatología sugerente de COVID-19 en la población se realiza el presente estudio. Metodología: Se trató de un estudio descriptivo tipo transversal, bajo enfoque cuantitativo y cualitativo utilizando el método de muestreo por lote. La población de estudio fueron los habitantes de municipios en los cuales no se reportaban oficialmente casos activos de COVID-19. Se recolectaron datos mediante encuesta electrónica y se aplicaron pruebas rápidas de detección de anticuerpos (lgG e lgM). Resultados: se encuestó y realizó pruebas a 792 personas de 41 municipios del país. La positividad de contacto se encontró en el 6.2 \% (49/792). De estos, el 55.1 \% (27/49) son hombres. Los grupos de edad con menor cantidad de pruebas de contacto positivo por COVID-19 fueron entre los 10-19 años (3/49) y mayores de 60 años (6/49). El cuadro clínico consistió en fiebre, disminución del apetito, dificultad respiratoria y pérdida del gusto y olfato. El $49.2 \%$ (32/49) fueron asintomáticos. Conclusiones: Se demostró que hubo circulación del virus en la población de municipios en donde no se notificaron casos activos, 96 días después del primer caso confirmado en el país. La detección de anticuerpos específicos del virus podría ser importante en encuestas para infección asintomática en zonas donde el contacto es esperado.

Palabras clave: SARS-CoV-2, serología, Honduras.

\section{Abstract}

Introduction: In Honduras on March 12, 2020, the first case of COVID-19 caused by the SARS-CoV-2 was reported. From that moment on, a series of measures were adopted to slow down contact throughout the country. By June 2020 , cases are reported across the whole country. With the objective of identifying the presence and circulation of SARS-CoV-2, characterizing and identifying suggestive symptoms of COVID-19 in the population, the present study was carried out. Methodology: A descriptive cross-sectional study was carried out, using a quantitative and qualitative approach, using the LQAS sampling method. The study population was the inhabitants of the identified municipalities, with no current circulation data for SARS-CoV-2 or the municipalities whose last confirmed case was 21 days ago. The data was collected through an electronic survey, it was possible to apply rapid antibody detection tests (IgG and IgM). Results: 792 people from 41 municipalities of the country were surveyed and tested. Positivity of contact was found in 6.2\% (49/792). Of these, 55.1\% (27/49) are men. 61.2\% (30/49) are between 20 and 49 years old. The clinical symptoms found were fever, decreased appetite, respiratory distress, and loss of taste and smell, the 49.2\% (32/49) without symptoms. Conclusions: virus circulation was demonstrated in the population of municipalities in which no cases were officially reported and after 96 days of the first confirmed case in the country. Detection of virus-specific antibodies could be important in surveys for asymptomatic infection in areas where contact is expected.

Key Words: SARS-CoV-2, serology, Honduras. 
Recibido: 29 jul 2020 | Corregido: 11 nov 2020 | Aceptado: 16 nov 2020

\begin{abstract}
${ }^{1}$ Unidad de Epidemiología-Sistema Nacional de Gestión de Riesgo, Universidad Nacional Autónoma, Secretaría de Salud y Colegio Médico, HONDURAS. mariorenemejia@gmail.com. ORCID: https://orcid.org/0000-0002-5247-9127

${ }^{2}$ Unidad de Epidemiología-Sistema Nacional de Gestión de Riesgo, Colegio Médico, HONDURAS. lara.joseangel@gmail.com, ORCID:

https://orcid.org/0000-0002-6453-4787)

${ }^{3}$ Unidad de Epidemiología- Sistema Nacional de Gestión de Riesgo, Colegio Médico, HONDURAS. sjaraujo22@gmail.com, ORCID:

https://orcid.org/0000-0003-1487-2689

${ }^{4}$ Unidad de Epidemiología- Sistema Nacional de Gestión de Riesgo, Colegio Médico, HONDURAS.gramirez.proyectos@gmail.com, ORCID: https://orcid.org/0000-0001-6128-6477
\end{abstract}

\title{
1. Introducción
}

En diciembre de 2019, se reportó una serie de casos de neumonía de etiología desconocida en la ciudad de Wuhan, China. La OMS solicitó a las autoridades nacionales que le facilitaran más información, a fin de evaluar el riesgo. Los signos y síntomas clínicos son principalmente fiebre, además, algunos pacientes sufren dificultades respiratorias y las radiografías de tórax muestran lesiones invasivas en ambos pulmones (Organización Mundial de la Salud, 2020). El 12 de enero de 2020 la Organización Mundial de la Salud (OMS/WHO) nombró este nuevo virus como el nuevo coronavirus 2019 y el 30 de enero de 2020 lo declara una emergencia de salud pública de importancia internacional. El 11 de febrero el Comité Internacional de Taxonomía de Virus lo nombra como síndrome respiratorio agudo severo (SARS-CoV-2) ( Sun, Lu, Xu, Sun y Pan, 2020).

Para finales de febrero del 2020, los casos confirmados de infección por SARS-CoV-2 en China ya excedían el número de infecciones del brote en 2002 por SARS en este país. (Sun et al., 2020). En Honduras, el primer caso positivo detectado se trata de una paciente embarazada de 42 años, quien ingresó al país el 4 de marzo por vía área sin presentar síntomas del coronavirus a la ciudad de Tegucigalpa, procedente de España. Fue diagnosticada el 12 de marzo (Despacho de Comunicaciones y Estrategia Presidencial, 2020b). 
Mediante Decreto Ejecutivo PCM-005-2020 de fecha 10 de febrero de 2020, se declaró estado de emergencia sanitaria en todo el territorio nacional, quedando restringida la libre circulación de personas a nivel nacional con algunas excepciones. Estas con el propósito de continuar y fortalecer las acciones de vigilancia, prevención, control y la atención a las personas ante la ocurrencia de infección por coronavirus (COVID-19) (Decreto Ejecutivo, N PCM-021-2020, 2020).

A raíz de la epidemia, Honduras como otros países del mundo redujo su actividad laboral presencial para minimizar en lo posible el contagio y entra en vigencia una ley que permite el comercio electrónico y el teletrabajo. Esta consiste en el desempeño de la actividad profesional sin la presencia física del trabajador, con el fin de mantener las actividades económicas en el país (Decreto Ejecutivo N PCM-005-2020, 2020).

Bajo la coordinación de la Unidad de Epidemiología del Sistema Nacional de Gestión de Riesgos (SINAGER), la Comisión Permanente de Contingencias (COPECO) y la cooperación de los epidemiólogos e integrantes de equipos de respuesta rápida de cada región sanitaria departamental del país, se lleva a cabo la presente investigación. Tiene el objetivo de identificar la presencia y circulación de SARS-CoV-2 en municipios del país que, a la fecha de su selección, oficialmente no reportaban casos o su último caso había sido reportado 21 o más días antes. Asimismo, encontrar factores asociados en la población de estudio e identificar sintomatología sugerente con presentación clínica de COVID-19.

\section{Referente teórico}

EI SARS-CoV-2 es un coronavirus $\beta$, que está envuelto en un virus de ARN de sentido positivo no segmentado. Anteriormente, se identificaron seis coronavirus como susceptibles a los humanos, entre los cuales los están a-CoV, HCoV-229E y HCoV-NL63, así como los $\beta-C o V$, HCoV-HKU1 y HCoV-OC43 con baja patogenicidad. Los primeros causan síntomas respiratorios leves similares a un resfriado común. Los otros dos $\beta-\mathrm{CoV}$, conocidos como SARS-CoV y MERS-CoV, conducen a infecciones respiratorias graves y potencialmente fatales (Yin y Wunderink, 2018).

Al ser una enfermedad respiratoria aguda, se propaga principalmente de persona a persona por gotitas y secreciones respiratorias. El período de incubación va desde 1 a 14 días, generalmente, de 3 a 7 días. Durante el período de latencia es posible el contagio. Puede generar complicaciones principalmente en 
personas adultas mayores y con enfermedades que comprometen el sistema inmune (Guo et al., 2020). De acuerdo con distintos estudios, la mediana de edad de pacientes es de 47 a 59 años y, el alrededor del 43,8 $\%$, son mujeres. Generalmente, se presentan síntomas leves similares a la gripe como fiebre, malestar general y tos. Algunos casos desarrollan síndrome de dificultad respiratoria e insuficiencia orgánica, que puede llevar a la muerte (Guo et al., 2020).

A nivel mundial, al 15 de junio de 2020, han habido 7823324 casos confirmados de COVID-19, incluidas 432757 muertes, reportados a la OMS (2020). Para la misma fecha, según los datos oficiales del Estado de Honduras, se notifican 9178 casos confirmados y 320 fallecidos. A nivel mundial, al 20 de julio de 2020, ha habido 14043176 casos confirmados de COVID-19, incluidas 597583 muertes, reportados a la OMS (2020) .Para la misma fecha, según los datos oficiales del Estado de Honduras se notifican 32793 casos confirmados y 891 fallecidos (Despacho de Comunicaciones y Estrategia Presidencial, 2020a).

La prueba más confiable y de más uso para el diagnóstico de COVID-19 ha sido la prueba de RT-PCR, realizada con hisopos nasofaríngeos u otras muestras del tracto respiratorio superior (Sethuraman, Jeremiah y Ryo, 2020). Pero la infección por COVID-19 también se puede detectar evaluando la respuesta inmune del huésped a la infección por SARS-CoV-2. Con lo anterior, se puede brindar un diagnóstico serológico importante a personas con enfermedad leve a moderada que pueden presentarse más allá de las primeras semanas de inicio de la enfermedad (Sethuraman et al., 2020). El diagnóstico serológico puede ser una herramienta importante para comprender el alcance de COVID-19 en una comunidad, así como identificar personas de alto riesgo o personas que pudieron haberse contagiado de la infección de manera asintomática.

La producción de anticuerpos específicos contra el virus SARS-CoV-2 es consistente en la mayoría de los pacientes, excepto en casos de inmunodeficiencia. La lgM puede detectarse 3 días después de que la infección alcanza su nivel máximo en 2-3 semanas, después de lo cual el nivel disminuye y proporciona la primera línea de defensa de inmunidad. Después de lo anterior, se inician las respuestas de lgG, la cual aumenta rápidamente, comenzando un poco más tarde en comparación con lgM, y se mantiene en un nivel alto durante 2 meses siendo clave en la memoria inmune a largo plazo. Los niveles detectables de anticuerpos IgM e lgG proporcionan información sobre el curso serológico de la enfermedad, ya que la 
detección de anticuerpos IgM indica una exposición reciente al SARS-CoV-2 y la detección de anticuerpos IgG en ausencia de anticuerpos IgM detectables indica exposición previa al virus.

La positividad de lgM o lgG no es significativamente diferente entre personas con síntomas leves, graves y críticos. Sin embargo, al análisis cualitativo, los niveles de anticuerpos durante el curso de la enfermedad revelan que los niveles de IgM específicos del SARS-CoV-2 son más altos y los niveles de lgG son más bajos en los pacientes en estado crítico, lo que podría deberse a un alto nivel de lgM o una respuesta inmune comprometida en estos pacientes (Hou et al., 2020).

\section{Metodología}

\subsection{Enfoque}

Se realizó un estudio transversal y descriptivo con un enfoque cuantitativo y cualitativo, basado en dos métodos probabilísticos de muestreo de amplio reconocimiento científico y probada efectividad; a saber, sitio centinela y muestreo por lote (LQAS), con el objetivo de identificar la presencia y circulación de SARSCoV-2.

El método de muestras por lote está basado en una muestra aleatoria simple estratificada de un pequeño número de unidades geográficas por estrato, también llamado 'lote o cuadra'. Es especialmente adecuado para encuestas de monitoreo y cobertura (Valadez, Weiss, Leburg y Davis, 2002). Del 16 al 23 de junio del 2020, se encuestaron 41 lotes poblacionales, con un estimado poblacional de aproximadamente 1100000 habitantes.

Se eligió una regla de decisión de 19 habitantes por lote para capturar un punto de referencia de cobertura de $\geq 95 \%$. Para el método de muestras por lote, una muestra de este tamaño da como resultado errores de clasificación (alfa y beta) de $<10 \%$.

La utilización de la técnica de los sitios centinelas se seleccionó porque tiene especial aplicación en sociedades con un sistema informático deficiente. Las poblaciones centinela fueron seleccionadas como muestras representativas relevantes para la investigación, construida mediante la agregación de 
segmentos poblacionales que comparten las siguientes características: identidad tipológica, territorios con similar dinámica poblacional y que presentan una dinámica de comunicación.

\subsection{Población y muestra}

Para la selección de la muestra, se consideró la información oficial de la Secretaría de Salud (SESAL) de los 298 municipios del país para la fecha del estudio, así como los criterios de inclusión y de exclusión. Con base en lo anterior, se seleccionaron los municipios y como unidad de análisis la vivienda. Esto para identificar el individuo al que se le aplicará la encuesta y la prueba sanguíneo. Fue seleccionada la persona cuya fecha de cumpleaños tuviera la mayor cercanía a la fecha de toma de muestra. Se muestrearon y recolectaron datos a un total de 792 personas.

\subsubsection{Características de los municipios seleccionados:}

Se incluyeron 16 departamentos del país, en cada departamento fueron seleccionados municipios sin datos de circulación activa de SARS-CoV-2, que cumplieran con todas las siguientes características:

\subsubsection{Características del municipio (lote) a seleccionar}

1. Núcleo poblacional con mayor/alto registro de enfermedad respiratoria agudas (ERAs) en el último mes, determinado mediante el formulario de enfermedades y eventos de notificación obligatoria (TRANS -1) de la Unidad local de salud y determinado por el epidemiólogo local.

2. Estructuras habitacionales de considerable aglomeración poblacional en comparación con otros municipios de su departamento.

3. Núcleos de tránsito y comercio concentrado con alta circulación de personas que facilitan la transmisión.

4. Alta densidad poblacional relativa al compararse con otros municipios de su departamento.

Se identificaron 41 municipios que cumplían con todos los criterios requeridos.

\subsubsection{Características de la vivienda a seleccionar}

Dado que la información sobre el número de viviendas en una determinada localidad y la población son estimaciones aproximadas, para la selección aleatoria tanto de la localidad como de la vivienda se realizó el siguiente método: 
1. En cada municipio seleccionado se hizo un listado de localidades (barrios, colonias, comunidades) que cumplían con los criterios de selección.

2. De manera aleatoria se escogió una localidad.

3. De no estar definidas las cuadras, se podía elaborar un mapa a mano alzada de la comunidad y establecer arbitrariamente las mediciones de forma que grupos de casas quedaran distribuidos casi de manera homogénea. Esto garantizó que las cuadras tuvieran casas y que estas fueran más que el número de muestras que se iban a levantar.

4. En la localidad seleccionada, partiendo del censo de vivienda, se escogió un conglomerado poblacional donde se aplicaron las 19 muestras. Una vez escogido el conglomerado poblacional, se tuvo la posibilidad de empezar de cualquiera de los 4 puntos cardinales (norte, sur, este, oeste), lo cual se resolvió con una rifa.

5. Una vez seleccionado el punto, se decidió lanzando una moneda al aire si se tomaba la ruta hacia arriba o hacia abajo.

6. Se aplico la técnica de reemplazo, si no había personas o nadie deseaba participar en la casa seleccionada se dirigía a la vivienda que esta antes o después.

\subsubsection{Características de la persona a seleccionar}

La persona a la que se le tomo la muestra y realizó la encuesta estuvo a cargo del equipo de trabajo de campo, bajo la supervisión de un miembro del grupo de investigadores. Se seleccionó a quien cumpliera todos los siguientes criterios:

De inclusión:

1. Persona mayor de 5 años

2. Persona cuya fecha de cumpleaños fuera la más cercana al día de realización de la prueba y aceptara participar en el estudio.

3. En caso de que la primera no aceptara, se escogía a la siguiente persona cuya fecha de cumpleaños fuera la más cercana al día de realización de la prueba (técnica de reemplazo).

Para las personas menores de edad, se solicitó consentimiento informado de los padres, las madres o tutores legales, así como el asentimiento de las niñas y los niños. Las personas mayores de 18 años firmaron consentimiento informado. 
De exclusión:

1. Persona que dio negativa a dar asentimiento o consentimiento informado

2. Persona con contraindicación para la punción capilar (edema, perfusión insuficiente, trastornos de coagulación)

3. Menores de 5 años por la dificultad para tomarles muestra sanguínea y recibir el asentimiento.

\subsection{Técnicas de recolección}

La recopilación de datos y toma de muestra se realizó bajo la supervisión de un médico de nivel local, una licenciada en enfermería, un técnico de laboratorio y un técnico de salud ambiental, los cuales fueron capacitados y dotados de equipo de protección personal básico. El periodo de estudio correspondió del 16 al 23 de junio de 2020.

Recolección de datos: se encuestó y realizó pruebas rápidas para la detección del antígeno lgG/lgM de SARS-CoV-2 con $93.4 \%$ de sensibilidad y $97.7 \%$ de especificidad.

Procesamiento y análisis de datos: la recolección de datos se realizó utilizando una encuesta en línea en el dispositivo móvil de un miembro del equipo, en una aplicación desarrollada en Epicollect 5. Se obtuvo una base de datos que fue revisada y analizada usando el software MS Excel versión 2016. Para las variables cuantitativas, se identificó que no cumplieron distribución normal por medio del estadístico KolmogórovSmirnov, por lo que se utilizó mediana como medida de tendencia central y rango intercuartil como medida de dispersión.

Consideraciones éticas: la presente investigación fue evaluada por un comité de bioética. No se utilizó el nombre ni identificación de las personas participantes, asegurando la confidencialidad de la información.

\section{Resultados}

Durante el periodo del 16 al 23 de junio de 2020 se encuestaron y aplicaron pruebas rápidas para detección de anticuerpos SARS-CoV-2 (IgG e IgM) a población general de 16 departamentos en 41 municipios de 
Honduras (ver figura 1). Se recolectaron datos de 792 individuos. Los departamentos donde se encontró positividad de contacto con el virus SARS-CoV-2 se muestran en la tabla 1.

\section{Tabla 1}

Prueba de contacto SARS-CoV-2 positiva según departamento y municipio de procedencia, Honduras. Periodo 16- 23 junio 2020.

\begin{tabular}{|c|c|c|c|c|}
\hline Departamento & Municipio & PRR & Positivas & $\%$ Positividad \\
\hline \multirow[t]{4}{*}{ Atlántida } & El Porvenir & 19 & 0 & 0.0 \\
\hline & Jutiapa & 19 & 0 & 0.0 \\
\hline & La Másica & 19 & 1 & 5.3 \\
\hline & Total & 57 & 1 & 1.8 \\
\hline \multirow{4}{*}{ Choluteca } & San Marcos De Colón & 18 & 9 & 50.0 \\
\hline & Duyure & 19 & 0 & 0.0 \\
\hline & Apacilagua & 17 & 4 & 23.5 \\
\hline & Total & 54 & 13 & 24.1 \\
\hline \multirow[t]{4}{*}{ Colón } & Limón & 19 & 1 & 5.3 \\
\hline & Bonito Oriental & 19 & 0 & 0.0 \\
\hline & Sonaguera & 19 & 2 & 10.5 \\
\hline & Total & 57 & 3 & 5.3 \\
\hline \multirow[t]{5}{*}{ Comayagua } & La Libertad & 19 & 0 & 0.0 \\
\hline & La Trinidad & 19 & 1 & 5.3 \\
\hline & Lejamaní & 19 & 1 & 5.3 \\
\hline & Lamaní & 19 & 1 & 5.3 \\
\hline & Total & 76 & 3 & 3.9 \\
\hline \multirow[t]{3}{*}{ Copan } & Florida & 19 & 5 & 26.3 \\
\hline & Nueva Arcadia & 19 & 2 & 10.5 \\
\hline & Total & 38 & 7 & 18.4 \\
\hline \multirow[t]{4}{*}{ El Paraíso } & Trojes & 19 & 3 & 15.8 \\
\hline & Oropoli & 19 & 1 & 5.3 \\
\hline & Teupasenti & 17 & 3 & 17.6 \\
\hline & Total & 55 & 7 & 12.7 \\
\hline \multirow[t]{3}{*}{ Francisco Morazán } & Cantarranas & 19 & 0 & 0.0 \\
\hline & Cedros & 19 & 1 & 5.3 \\
\hline & Total & 38 & 1 & 2.6 \\
\hline \multirow[t]{4}{*}{ Gracias A Dios } & Ahuas & 19 & 2 & 10.5 \\
\hline & Puerto Lempira & 21 & 1 & 4.8 \\
\hline & Brus Laguna & 19 & 0 & 0.0 \\
\hline & Total & 59 & 3 & 5.1 \\
\hline \multirow[t]{3}{*}{ Intibucá } & Yamaranguila & 19 & 0 & 0.0 \\
\hline & San Isidro & 19 & 0 & 0.0 \\
\hline & Colomoncagua & 19 & 0 & 0.0 \\
\hline
\end{tabular}




\begin{tabular}{|c|c|c|c|c|}
\hline \multirow{3}{*}{ La Paz } & & & & \\
\hline & La Paz & 24 & 0 & 0.0 \\
\hline & Total & 24 & 0 & 0.0 \\
\hline \multirow{3}{*}{ Lempira } & Lepaera & 18 & 0 & 0.0 \\
\hline & Gracias & 19 & 2 & 10.5 \\
\hline & Total & 37 & 2 & 5.4 \\
\hline \multirow[t]{3}{*}{ Ocotepeque } & Ocotepeque & 18 & 0 & 0.0 \\
\hline & Concepción & 19 & 0 & 0.0 \\
\hline & Total & 37 & 0 & 0.0 \\
\hline \multirow[t]{4}{*}{ Olancho } & Catacamas & 19 & 0 & 0.0 \\
\hline & Salamá & 19 & 0 & 0.0 \\
\hline & $\begin{array}{l}\text { San Francisco De La } \\
\text { Paz }\end{array}$ & 19 & 0 & 0.0 \\
\hline & Total & 57 & 0 & 0.0 \\
\hline \multirow[t]{4}{*}{ Santa Bárbara } & Concepción Del Norte & 20 & 1 & 5.0 \\
\hline & Atíma & 20 & 0 & 0.0 \\
\hline & Santa Rita & 19 & 0 & 0.0 \\
\hline & Total & 59 & 1 & 1.7 \\
\hline \multirow[t]{3}{*}{ Valle } & $\begin{array}{l}\text { Goascorán (El } \\
\text { Amatillo) }\end{array}$ & 19 & 5 & 26.3 \\
\hline & $\begin{array}{l}\text { San Francisco De } \\
\text { Coray }\end{array}$ & 18 & 0 & 0.0 \\
\hline & Total & 37 & 5 & 13.5 \\
\hline \multirow[t]{3}{*}{ Yoro } & Sulaco & 25 & 2 & 8.0 \\
\hline & Yorito & 25 & 1 & 4.0 \\
\hline & Total & 50 & 3 & 6.0 \\
\hline Total, general & & 792 & 49 & 6.2 \\
\hline
\end{tabular}

PPR: Pruebas rápidas realizadas.

Fuente: Elaboración propia.

El 6.2\% de las pruebas rápidas aplicadas (49/792) resultaron positivas. Los departamentos en los cuales la totalidad de las muestras fueron negativas son Intibucá, La Paz, Ocotepeque y Olancho, como se muestra en la figura 1. 


\section{Figura 1}

Distribución de localidades municipales con contactos positivos y negativos

por SARS-CoV-2 Honduras. Periodo 16-23 junio 2020. $n=792$

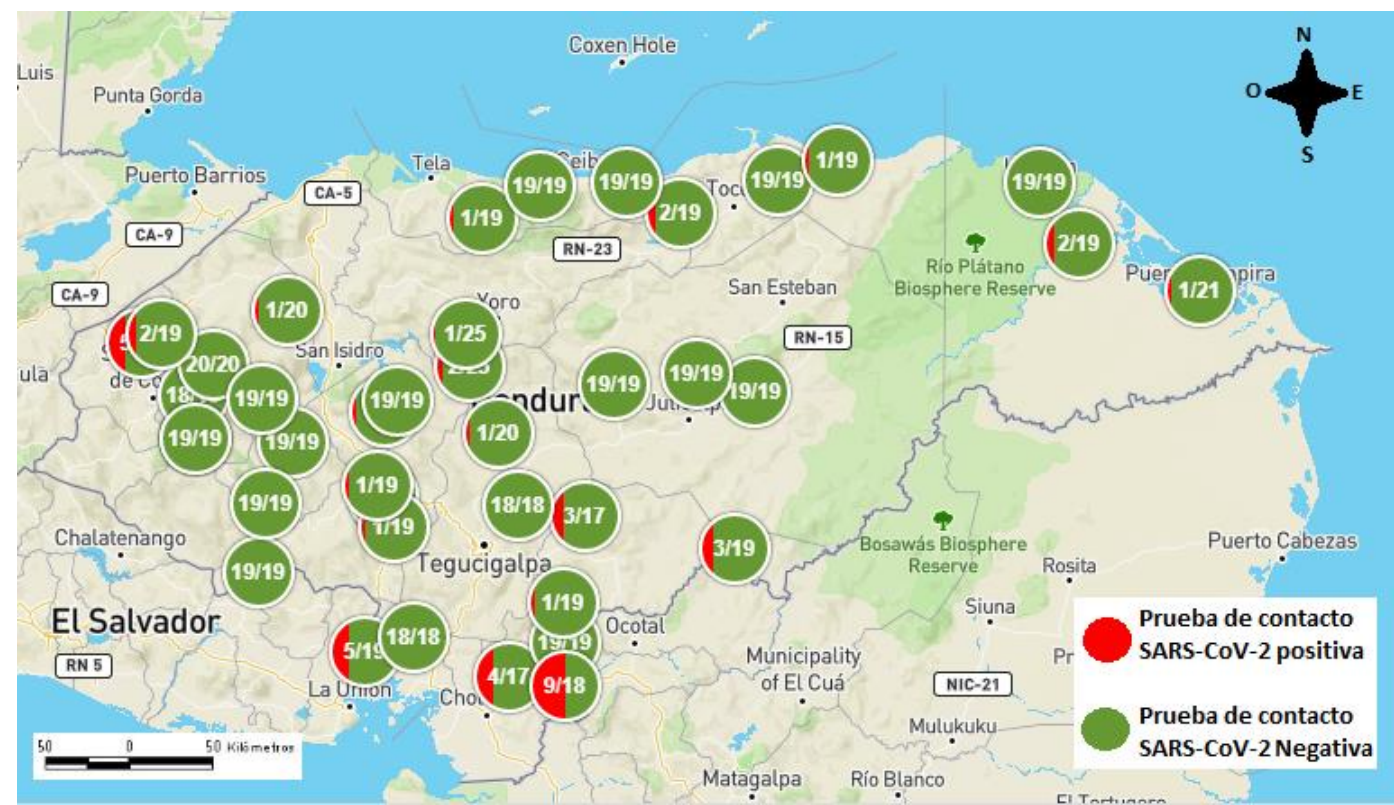

Fuente: Elaboración propia.

La distribución de resultados de las pruebas se puede observar en la tabla 2.

\section{Tabla 2}

Distribución de resultados de prueba rápida para detección de SARS-CoV-2

Honduras. Periodo 16-23 junio 2020

\begin{tabular}{lcc} 
Prueba rápida & No. & $\%$ \\
Negativo & 743 & 93.8 \\
Positivo & 49 & 6.2 \\
Total & 792 & 100.0 \\
\hline
\end{tabular}

Fuente: Elaboración propia.

En la figura 2 se describe la muestra por grupos de edad, cuya mediana es de 37 años, con un rango intercuartil de 27 a 50 años). Los grupos de 20 a 39 años tuvieron el 50 \% (394/792) de las pruebas realizadas (eje "y" izquierdo). Los porcentajes de positividad (eje " $y$ " derecho) variaron entre 2.6 \% para el grupo de edad de 30 a 39 y $8.5 \%$ para el grupo de 50 a 59 años. 


\section{Figura 2}

Prueba de contacto SARS-CoV-2 positiva según por grupo de edad Honduras. Periodo 16-23 junio 2020.

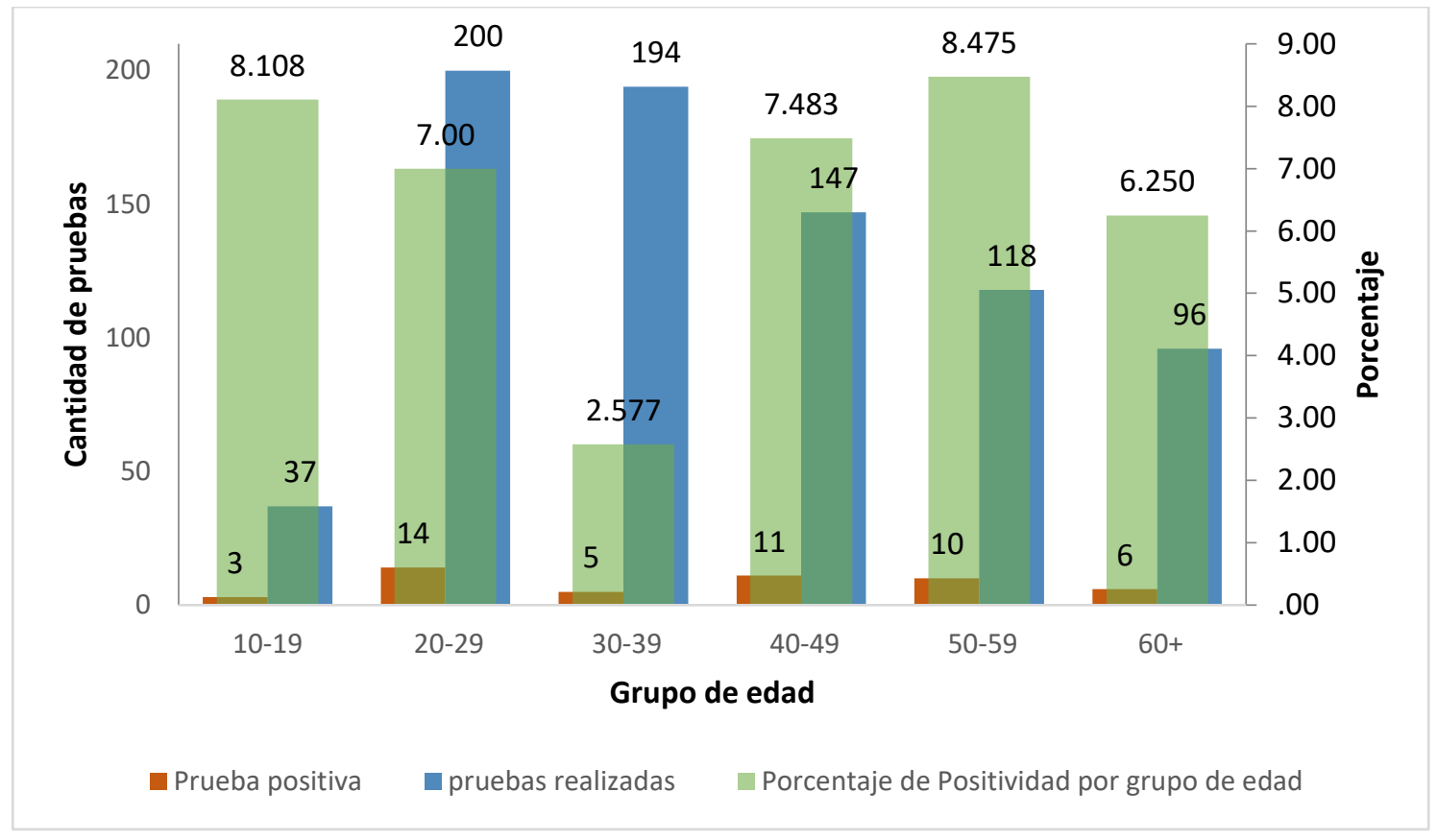

Fuente: Elaboración propia

La distribución de pruebas rápidas realizadas para detección de COVID-19 correspondió a un 43.5 \% de hombres (359/792) y $54.7 \%$ (433/792) de mujeres. De estas, tuvieron resultado de contacto SARS-CoV-2 positivo el $55.1 \%$ (27/49) de los hombres y $44.9 \%$ (22/49) las mujeres (ver figura 3).

\section{Figura 3}

Prueba de contacto SARS-CoV-2 positiva, según sexo Honduras. Periodo 16-23 junio 2020.

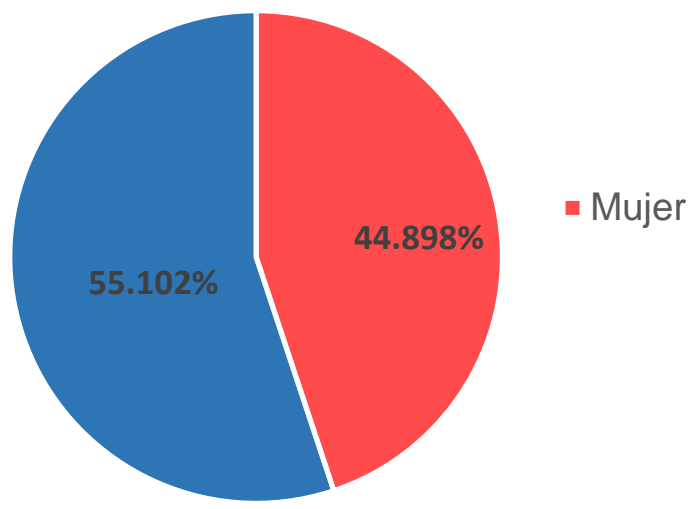

Fuente: Elaboración propia. 
De la población estudiada, el 23.4\% (185/792) de las personas reportaron la presencia de comorbilidad. Mujeres mayores de 60 años en un el 61.1 \% (113/185). La comorbilidad está presente en el 30.6 \% (15/49) de los contactos positivos, tanto hombres como mujeres. Hay concentración en población mayor de los 40 años. El 53 \% (8/15) fueron hombres mayores de 50 años. En la Tabla 3 se observa el detalle por grupos de edad.

\section{Tabla 3}

Prueba de contacto SARS-CoV-2 positiva según comorbilidad por sexo y grupo de edad, Honduras. Periodo 16- 23 junio 2020.

\begin{tabular}{|c|c|c|c|c|c|c|c|}
\hline \multirow{3}{*}{ Sexo } & \multirow{3}{*}{$\begin{array}{c}\text { Grupo de } \\
\text { edad }\end{array}$} & \multicolumn{4}{|c|}{ Comorbilidad } & \multirow{2}{*}{\multicolumn{2}{|c|}{ Total }} \\
\hline & & \multicolumn{2}{|c|}{ Si } & \multicolumn{2}{|c|}{ No } & & \\
\hline & & No. & $(\%)$ & No. & $(\%)$ & No. & $(\%)$ \\
\hline \multirow{7}{*}{ Hombre } & $10-19$ & 0 & 0.0 & 0 & 0.0 & 0 & 0.0 \\
\hline & $20-29$ & 1 & 6.7 & 6 & 17.6 & 7 & 14.3 \\
\hline & $30-39$ & 0 & 0.0 & 4 & 11.8 & 4 & 8.2 \\
\hline & $40-49$ & 2 & 13.3 & 4 & 11.8 & 6 & 12.2 \\
\hline & $50-59$ & 3 & 20.0 & 4 & 11.8 & 7 & 14.3 \\
\hline & $60+$ & 3 & 20.0 & 0 & 0.0 & 3 & 6.1 \\
\hline & Total & 9 & 60.0 & 18 & 52.9 & 27 & 55.1 \\
\hline \multirow{7}{*}{ Mujer } & $10-19$ & 0 & 0.0 & 3 & 8.8 & 3 & 6.1 \\
\hline & $20-29$ & 0 & 0.0 & 7 & 20.6 & 7 & 14.3 \\
\hline & $30-39$ & 0 & 0.0 & 1 & 2.9 & 1 & 2.0 \\
\hline & $40-49$ & 2 & 13.3 & 3 & 8.8 & 5 & 10.2 \\
\hline & $50-59$ & 1 & 6.7 & 2 & 5.9 & 3 & 6.1 \\
\hline & $60+$ & 3 & 20.0 & 0 & 0.0 & 3 & 6.1 \\
\hline & Total & 6 & 40.0 & 16 & 47.1 & 22 & 44.9 \\
\hline \multicolumn{2}{|c|}{ Total, general } & 15 & 100.0 & 34 & 100.0 & 49 & 100.0 \\
\hline
\end{tabular}

Fuente: Elaboración propia 2020 
La actividad laboral presencial, es decir, fuera de la casa es realizada por el 63.1 \% (500/792) de la población encuestada. En dicha población, el 53.1 \% (26/49) resultó con prueba positiva de contacto SARS-CoV-2 (ver Figura 4).

\section{Figura 4}

Prueba de contacto SARS-CoV-2 positiva, según por tipo de actividad laboral Honduras. Periodo 16- 23 junio 2020.

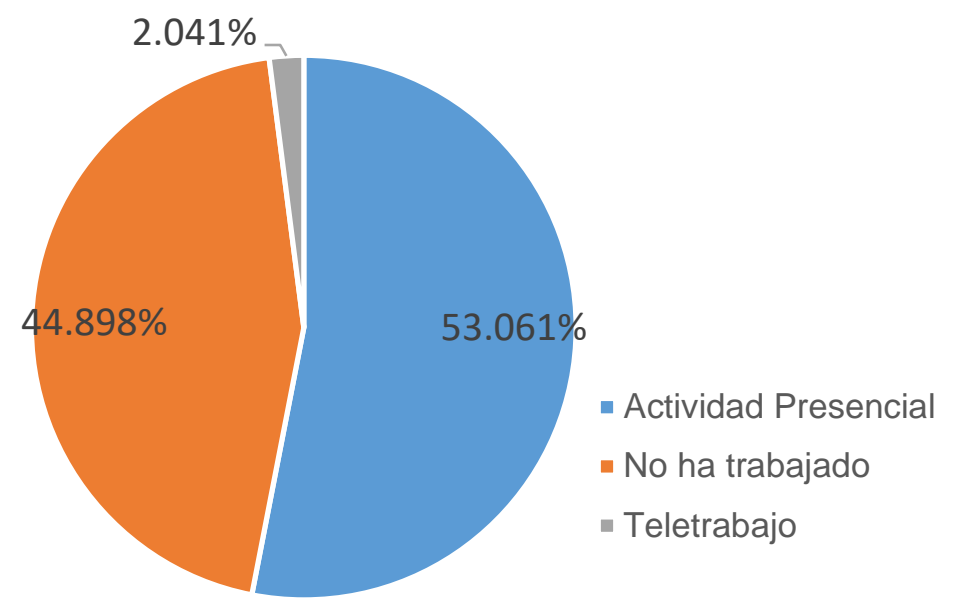

Al interrogar de manera dirigida sobre la existencia de signos o síntomas de patología respiratoria aguda, el $49.2 \%$ (32/49) de las personas con prueba de contacto SARS-CoV-2 positivo refirieron no presentar signos o síntomas. De las personas que reportaron cuadro clínico, este se caracterizó por fiebre (10.8\%; $7 / 49)$, disminución del apetito $(7.7 \% ; 5 / 49)$, perdida del gusto $(7.7 \% ; 5 / 49)$ y dificultad respiratoria $(6.2 \%$; 4/49) (Ver Figura 5). 


\section{Figura 5}

Cuadro clínico de personas con SARS-CoV-2 positivo

Honduras. Periodo 16- 23 junio 2020.

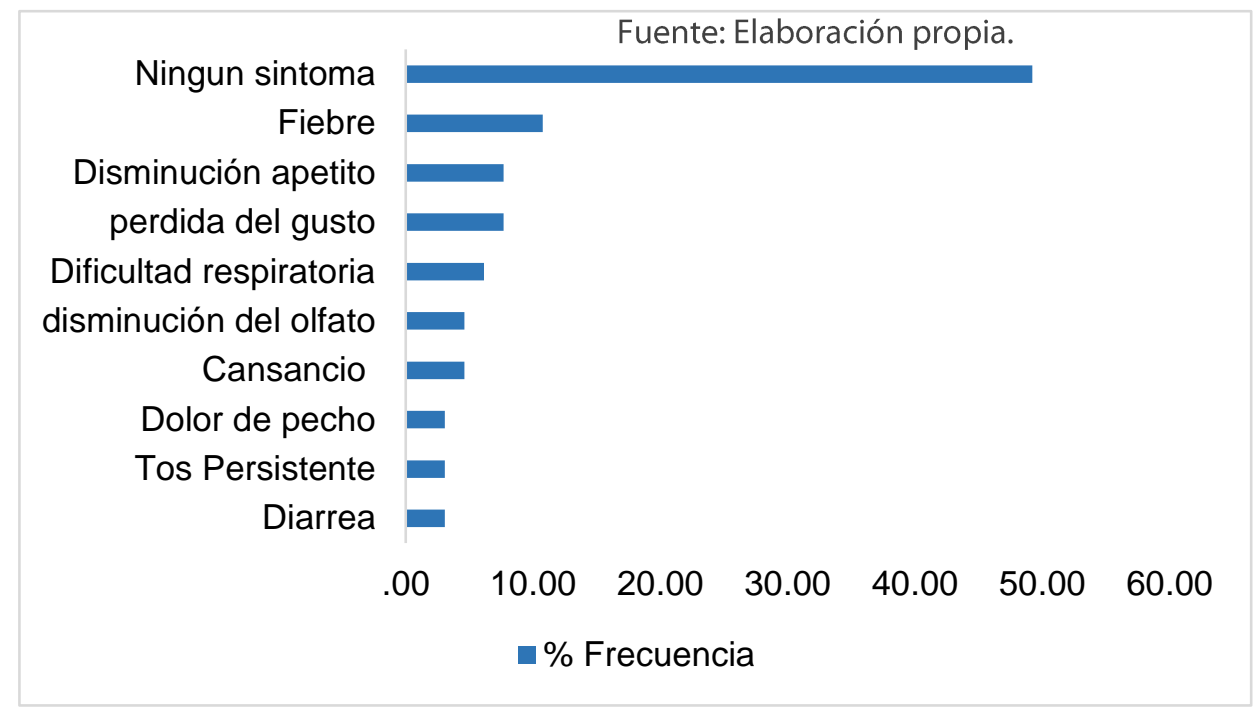

Reportamos respuestas agudas de anticuerpos al SARS-CoV-2 en 49 personas. El $30.6 \%$ (15/49) dieron positivo por antiviral inmunoglobulina-G (IgG). La positividad específica para IgG e IgM ocurrió en el 34.7 $\%(17 / 49)$. El $80 \%(12 / 15)$ de las personas cuya prueba detecto IgM positivo, no reportaron signos o síntomas (Ver tabla 4).

\section{Tabla 4}

Prueba de contacto SARS-CoV-2 positiva según tipo de anticuerpo detectado, Honduras. Periodo 16-23 junio 2020.

\begin{tabular}{lcc} 
& \multicolumn{2}{c}{ Positivo } \\
\cline { 2 - 3 } Resultado. & $\%$ \\
IgM & 15 & 30.6 \\
IgG & 17 & 34.7 \\
IgM-IgG & 17 & 34.7 \\
Total & 49 & 100.0 \\
\hline
\end{tabular}

Fuente: Elaboración propia. 


\section{Discusión}

Fue posible encontrar contactos positivos con el virus SARS-CoV-2 en la mitad de los municipios en los que se realizó la intervención. Resaltan municipios como San Marcos de Colon (Choluteca), La Florida (Copan), Trojes (El Paraíso) y El Amatillo Goascorán (Valle), los cuales se ubican en puntos fronterizos del país, lo que podría sugerir un control deficiente en el movimiento poblacional en estas áreas. Tomando en cuenta los criterios de selección de localidad, se encontró una positividad promedio de 6.2 \% (49/792).

Los grupos de edad con menor cantidad de pruebas de contacto positivo COVID-19 fueron entre los 1019 años (3/49) y los mayores de 60 años (6/49). De las pruebas realizadas, se encontró que la positividad por grupo de edad varió entre 2.6 \% para el grupo de edad de 30 a 39 y 8.5 \% para el grupo de 50 a 59 años. Un estudio que semanalmente estimó la seroprevalencia de anticuerpos anti-SARS-CoV-2 en 2766 participantes de la población de Ginebra, Suiza, durante la epidemia, observó después de 5 semanas que en los niños pequeños de 5 a 9 años el riesgo de ser seropositivos fue menor que en los de 20 a 49 años. Del mismo modo, los mayores de 65 años tenían un menor riesgo de ser seropositivos que los de 20 a 49 años. Lo anterior, valorando una seroprevalencia final de $10.8 \%$ (Stringhini et al., 2020). Los datos de edad nos sugieren que en gran parte es la población económicamente activa la que parece ser más prevalente en esta pandemia.

La seropositividad fue similar entre mujeres y hombres. De estos, los mayores de 50 años reportaron mayor frecuencia de comorbilidades en relación con las mujeres. Esta evidencia sugiere que las comorbilidades crónicas pueden ser factores de riesgo determinantes para la progresión a enfermedad severa en pacientes con COVID-19 (Gao et al., 2020). Un metaanálisis, basado en datos de siete estudios de casos de COVID-19 confirmado por laboratorio, observó mayor proporción de pacientes hombres que mujeres (890:686). Este dato, a su vez, era consistente con el Centro Chino para Control y Prevención de Enfermedades (China CDC) (Yang et al., 2020). Las diferencias de sexo en las respuestas inmunitarias dan como resultado una susceptibilidad diferencial de hombres y mujeres a enfermedades autoinmunes, tumores malignos y enfermedades infecciosas. Independientemente de la edad, las mujeres tienden a mostrar mayores 
respuestas de anticuerpos que los hombres, mayores niveles de inmunoglobulina basal y mayor número de células B1. La mayor inmunidad a los patógenos entre las mujeres podría contribuir a una menor carga viral en las mujeres que en hombres (Klein y Flanagan, 2016).

La actividad laboral presencial es predominante en la población encuestada con resultado positivo de contacto. La Secretaría de Trabajo de Honduras, en conjunto con otras entidades, estableció protocolos que tienen como objetivo que se apliquen medidas de bioseguridad que permitan preparar a las empresas para una apertura paulatina, ordenada y segura de la actividad laboral. Desgraciadamente, estas parecen no efectuarse o no acatarse correctamente en todos los sectores laborales de distintos municipios del país.

La mitad de las personas con prueba de contacto SARS-CoV-2 positivo no refirieron signos o síntomas y los que lo hicieron refirieron principalmente fiebre, disminución del apetito y pérdida del gusto. En pacientes de Wuhan, China, se determinó que la mayoría de los pacientes con COVID-19 tienen una enfermedad leve y se recuperan rápidamente después de una intervención clínica adecuada. Solo algunos pacientes con COVID-19 desarrollan síndrome respiratorio agudo grave (SRAS), insuficiencia orgánica múltiple e incluso la muerte (Hou et al., 2020).

Personas con lgG o lgM positivos que presentaron clínica de la enfermedad refirieron que su fecha de inicio de síntomas tuvo lugar entre una y cuatro semanas previas a la realización de la prueba. De acuerdo con Sethuraman et al. (2020), el lgM e lgG pueden determinar resultados positivos incluso tan pronto como el cuarto día después del inicio de los síntomas, aunque niveles más altos de seropositividad ocurren entre la segunda y tercera semana de enfermedad. Entre la tercera y cuarta semana del inicio de las manifestaciones clínicas, la lgM comienza a disminuir y alcanza niveles más bajos en la quinta semana, casi desapareciendo para la séptima semana; mientras que la lgG persiste aún siete semanas después.

Se debe recordar que las pruebas serológicas de lgG e IgM especificas a SARS-CoV-2 no deben utilizarse como diagnóstico definitivo, sino que siempre es necesario el análisis molecular genético (Ramírez et al., 2020). El uso de pruebas rápidas puede ser beneficioso para medir la línea de base de los títulos de lgG e IgM COVID-19 en la población (John Hopkins Center for Health Security, 2020). 


\section{Conclusiones}

Se demostró circulación del virus en población de municipios en los cuales no se notificaban casos activos. A su vez, a pesar de la alta circulación reportada de SARS-CoV-2 en otros municipios del país, en su momento no encontramos evidencia de circulación del virus en varios de los municipios seleccionados. Para finales de julio de este año, municipios como puerto Lempira, Bonito Oriental, Sonagera, Nueva Arcadia, la Paz, La Másica, Gracias y Ocotepeque han reportado una elevación importante de casos, el resto de los municipios estudiados se mantenían en situación estable.

La población que tuvo contacto positivo con el virus fue principalmente masculina. La tercera parte presentó alguna comorbilidad y se encontró que la actividad laboral presencial era predominante en este grupo. La mitad de las personas con prueba de contacto SARS-CoV-2 positiva no refirió signos o síntomas y quienes reportaron cuadro clínico estuvo caracterizado principalmente por fiebre, disminución del apetito, perdida del gusto y dificultad respiratoria.

La detección de anticuerpos específicos de virus SARS-CoV-2 podría ser importante en encuestas para infección asintomática en zonas donde el contacto es esperado. Así mismo encontrar personas sospechosas de COVID-19 lo antes posible con la ayuda de serología podría reducir el riesgo de exposición de las personas, con lo cual se ahorra en pruebas de PCR-RT. En nuestro estudio, se encontraron 32 personas asintomáticas positivas lgG o lgM. Las pruebas serológicas pueden ser útiles para lograr estimaciones más precisas de la extensión e impacto del virus en Honduras.

Debido a la evolución de la pandemia del SARS-CoV-2, es importante aprovechar el momento para fortalecer el sistema de captación y seguimiento de personas sospechosas, ya que la vulnerabilidad de nuestros servicios de salud y el comportamiento de esta enfermedad favorecen a una saturación del sistema de atención en salud.

Las limitantes que se presentaron en este estudio fueron dificultad de desplazamiento dentro de localidades apartadas y alguna situación de rechazo ocasional a dar datos personales o permitir la toma de muestra dentro del hogar, por temor al estigma social que la enfermedad puede generar dentro de la comunidad o por la creencia de que las pruebas rápidas no funcionan. Por el estigma mencionado, algunas 
personas identificadas se desplazaron a establecimientos de salud para la toma de su muestra. A pesar de lo antes mencionado, todas las personas identificadas mediante el proceso de selección pudieron ser muestreadas.

\section{Referencias}

Decreto Ejecutivo N PCM-005-2020 (2020). Recuperado de https://www.tsc.gob.hn/web/leyes/Decreto33-2020.pdf

Decreto Ejecutivo, N PCM-021-2020 (2020). Recuperado de https://presidencia.gob.hn/index.php/salade-prensa/7016-decreto-ejecutivo-numero-pcm-021-2020

Despacho de Comunicaciones y Estrategia Presidencial. (2020a). Coronavirus COVID-19 En Honduras. Recuperado de https://covid19honduras.org/

Despacho de Comunicaciones y Estrategia Presidencial. (2020b). Recibe el alta la paciente cero, primer caso de COVID-19 en Honduras. Recuperado de https://covid19honduras.org/?q=paciente-cero-recibeel-alta

Gao, J., Huang, X., Gu, H., Lou, L. y Xu, Z. (2020). Predictive criteria of severe cases in COVID-19 patients of early stage. Research Square, [Preprint]. DOI: https://doi.org/10.21203/rs.3.rs-39161/v1

Guo, Y.-R., Cao, Q.-D., Hong, Z.-S., Tan, Y.-Y., Chen, S.-D., Jin, H.-J. y Yan, Y. (2020). The origin, transmission and clinical therapies on coronavirus disease 2019 (COVID-19) outbreak - an update on the status. Military Medical Research, 7(1), 11. Doi: https://doi.org/10.1186/s40779-020-00240-0

Hou, H., Wang, T., Zhang, B., Luo, Y., Mao, L., Wang, F. y Sun, Z. (2020). Detection of IgM and IgG antibodies in patients with coronavirus disease 2019. Clinical \& Translational Immunology, 9(5), e01136. Doi: https://doi.org/10.1002/cti2.1136 
John Hopkins Center for Health Security. (2020). Serology-based tests for COVID-19 [Sitio web]. Recuperado de https://www.centerforhealthsecurity.org/resources/COVID-19/serology/Serologybased-tests-for-COVID-19.html

Klein, S. L. y Flanagan, K. L. (2016). Sex differences in immune responses. Nature reviews Immunology, 16(10), 626-638. Doi: https://doi.org/10.1038/nri.2016.90

Organización Mundial de la Salud. (2020). Neumonía de causa desconocida - China: Brotes epidémicos. Recuperado de https://www.who.int/csr/don/05-january-2020-pneumonia-of-unkown-causechina/es/

Ramírez, P. A., Valencia, Y. E., Carrillo, C. Q., Ayala, E. V., Delgado, J. d. L. y Cruz, A. P. (2020). Pruebas diagnósticas para la COVID-19: la importancia del antes y el después. Horizonte MéDico (Lima), 20(2). Recuperado de http://www.horizontemedico.usmp.edu.pe/index.php/horizontemed/article/view/1231

Sethuraman, N., Jeremiah, S. S. y Ryo, A. (2020). Interpreting Diagnostic Tests for SARS-CoV-2. JAMA, 323(22). Doi: https://doi.org/10.1001/jama.2020.8259

Stringhini, S., Wisniak, A., Piumatti, G., Azman, A. S., Lauer, S. A., Baysson, H. y Guessous, I. (2020). Seroprevalence of anti-SARS-CoV-2 lgG antibodies in Geneva, Switzerland (SEROCoV-POP): a population-based study. The Lancet, 396(10247), 313-319. Doi: https://doi.org/10.1016/S0140$\underline{6736(20) 31304-0}$

Sun, P., Lu, X., Xu, C., Sun, W. y Pan, B. (2020). Understanding of COVID-19 based on current evidence. Journal of medical virology, 92(6), 548-551. Doi: https://doi.org/10.1002/jmv.25722

Valadez, J., Weiss, W., Leburg, C. y Davis, R. (2002). LQAS Participant's Manual 2007 - CORE Group. Recuperado de https://www.yumpu.com/en/document/read/22874006/lqas-participants-manual2007-core-group 
World Health Organization. (2020). Coronavirus Disease (COVID-19) Dashboard. Recuperado de https://covid19.who.int/?gclid=Cj0KCQjwvIT5BRCqARIsAAwwD-

SYDaVY b6viVz|43hDLUTB2Kkr0 ZcdeCiJab7ibeCv4sRtfowMkgaAoYSEALw wcB

Yang, J., Zheng, Y., Gou, X., Pu, K., Chen, Z., Guo, Q., Zhou, Y. (2020). Prevalence of comorbidities and its effects in patients infected with SARS-CoV-2: a systematic review and meta-analysis. International journal of infectious diseases, 94, 91-95. Doi: https://doi.org/10.1016/j.ijid.2020.03.017

Yin, Y. y Wunderink, R. (2018). MERS, SARS and other coronaviruses as causes of pneumonia. Respirology, 23(2), 130-137. Doi: https://doi.org/10.1111/resp.13196 


\section{Población y Salud en Mesoamérica}

¿Quiere publicar en la revista? Ingrese aquí

O escríbanos:

revista@ccp.ucr.ac.cr

\section{$1^{\circ}$ Revista}

\section{Electrónica UCR}

\section{3 años de liderazgo}

\section{UCR Index}

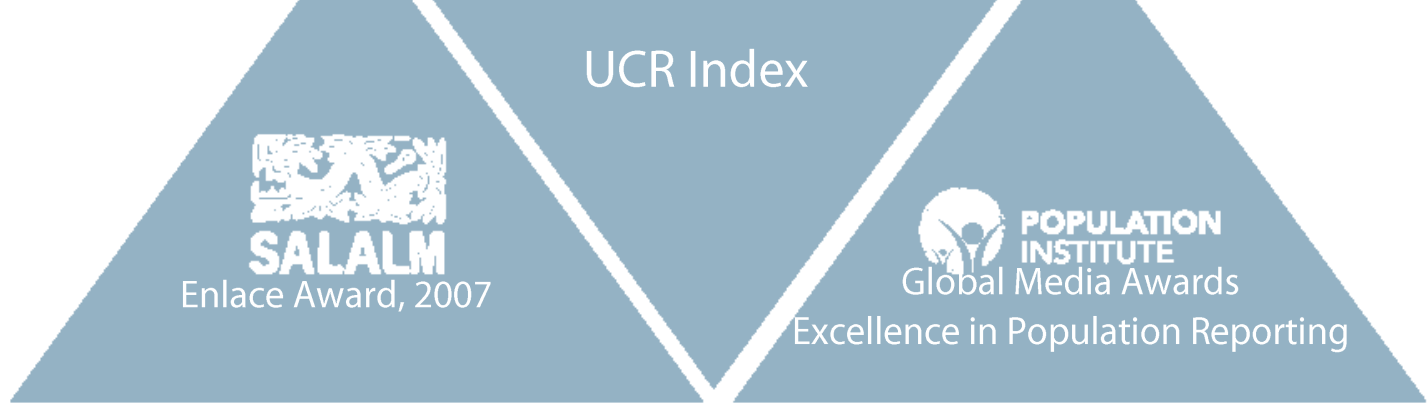

Población y Salud en Mesoamérica (PSM) es la revista electrónica que cambió el paradigma en el área de las publicaciones científicas electrónicas de la UCR. Logros tales como haber sido la primera en obtener sello editorial como revista electrónica la posicionan como una de las más visionarias.

\section{Revista PSM es la letra delta mayúscula, el cambio y el futuro.}

Indexada en los catálogos más prestigiosos. Para conocer la lista completa de índices, ingrese aquí.

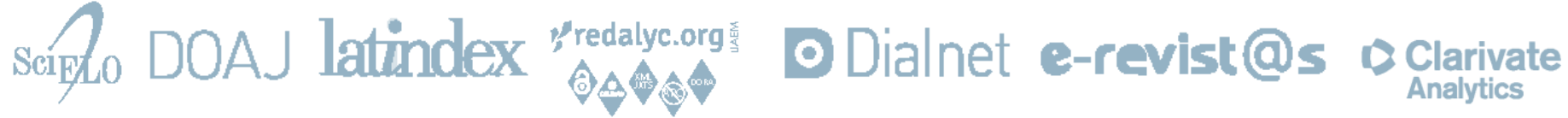

f Revista Población y Salud en Mesoamérica - PSM

Centro Centroamericano de Población

Universidad de Costa Rica

\section{(웅(-}

